\title{
Performance Evaluation of Realistic Mobility Models using Road Side Units
}

\author{
Divya Shree \\ Computer Science and Engineering Department \\ DCRUST, Murthal, \\ Sonepat, India
}

\author{
Dinesh Singh \\ Computer Science and Engineering Department \\ DCRUST, Murthal, \\ Sonepat, India
}

\begin{abstract}
Vehicular Ad Hoc Networks (VANETs) characterized by nodes with relatively high Mobility and various distributed environments represent a remarkable challenge dissimilar to MANETs. Applications of inter-vehicle and vehicle-toroadside wireless communication that make use of VANETs require reliable communication that provides a guarantee of real-time message propagation. In this thesis the performance of wireless VANET is evaluated by finding the impact of placement of Road Side Units on different Mobility Models by taking various parameters into consideration. For evaluation we use the network simulator NS-2 with a car traffic movement file of different scenarios generated by Mobility generator Vanet MobiSim, simulating the current WLAN hardware with the Ad hoc On Demand Distance Vector routing protocol (AODV). The connectivity tests have shown that it is a realistic option to use ad hoc networks for vehicular communication. But our simulations also have drawn out that placement of Road Side Units according to the type of Mobility Model used will lead to better communication.
\end{abstract}

\section{Keywords}

MANET, VANET, Mobility Model, RSU.

\section{INTRODUCTION}

Vehicular Ad-Hoc Network (VANET) communication has become an important and popular research topic in the area of wireless networking as well as the automotive industries. [4] The goal of VANET research is to provide safety and comfort to passengers by developing an efficient communication system. Due to the expensive cost of deploying and complexity of implementing such a system in real world, research in VANET depends on simulation, which correctly reflects the real-world performance of a VANET. A realistic mobility model should consist of a realistic topological map, which depicts the pattern of roads and streets with their speed limits and intersection points which is pictured by a real world map obtained by TIGER (Topologically Integrated Geographic Encoding and Referencing) line database from U.S. Census Bureau or by taking Satellite images of Google Earth for simulating a real world map and also depicts the behavior of the driver at the intersection (e.g. turn left, turn right or go straight). [5],[6] Multiple wireless technologies, such as 3G cellular systems, IEEE 802:11p, and IEEE $802: 16$ e, are used for effective Vehicle-to- Infrastructure (V2I) communications [2]. Also, V2V and V2I communication technology has been developed as part of the Vehicle Infrastructure Integration initiative [7], which considers the network infrastructure as composed by several Road Side Units (RSUs), equipped with a 5:9 GHz Dedicated Short Range Communication (DSRC) transceiver (i.e., for communications between vehicles and RSUs), and a GPRS interface (i.e., to forward messages to the backbone networks). In this paper, we check the impact on various mobility models of placement of Road Side Units at different distances by taking various parameters into consideration.

This paper is organized as follows. In Section II we investigate previous related works on Realistic Mobility Models in VANETs. Section III introduces the analysis taken by placing RSU on Mobility Models. Extensive simulation results are then shown in Section IV. Finally conclusions are drawn in Section V.

\section{RELATED WORK}

Calculates performance for different traffic and mobility patterns ranging from sparse traffic to congested traffic environment where both $\mathrm{V} 2 \mathrm{~V}$ and V2I connectivity are provided. VANET suffers from data delivery especially in sparse and totally disconnected scenarios (vehicle density is very low and null). [7]

Therefore three regions are taken: sparse traffic condition, dense traffic condition, congested traffic condition. Each region is tested:
I. By placing no RSU (Road Side Units)
II. By placing RSU at $1 \mathrm{~km}$ apart
III. By placing RSU at $2 \mathrm{~km}$ apart

Simulation results have been compared in 3 cases in terms of performance parameters throughput and end-to-end delay.

The Author "Nidhi and D.K.Lobiyal" [5] proposed in February 2012, evaluate the performance of VANET in a realistic environment by generating a real world road Map of JNU using existing Google Earth and GIS tools. The realistic mobility model used here considers the driver's route choice at the run time and studies the clustering effect caused by traffic lights used at the intersection to regulate traffic movement at different directions. Finally, the performance of the VANET is evaluated in terms of average delivery ratio, packet loss with traffic light scenario. This experiment has provided insight into the performance of vehicular traffic communication for a small realistic scenario.

The Authors "Irina Tal and Gabriel- Miro Muntean" [1] in 2011, the architecture of the proposed solution with the cluster-based mechanism is presented for multimedia transmissions and the cluster head selection algorithm required for delivery infrastructure management. Simulationbased testing demonstrates how this solution increases system stability resulting in a longer life of the elected cluster head compared to the classic. 
The Authors "Kun-chan Lan and Chien-Ming Chou" [8] in 2007 which introduces a tool MOVE that allows users to rapidly generate realistic mobility models for VANET simulations. MOVE is built on top of an open source microtraffic simulator SUMO. The output of MOVE is a realistic mobility model and can be immediately used by popular network simulators such as ns-2. Evaluate the effects of details of mobility models in three case studies of VANET simulations are evaluated and selecting sufficient level of details in the simulation is critical for VANET protocol design are shown.

The authors "Atulya Mahajan, Niranjan Potnis, Kartik Gopalan and An-I A. Wang" [9] in 2005 studies various Mobility Models that account for vehicular movement constraints such as traffic lights, multilane roads, and acceleration/deceleration. By comparing various Mobility Models effect on delivery ratio and packet delays are demonstrated at intersections. Routing performance is calculated by simulation of multiple lanes and synchronization of traffic lights. Their work provides a sound starting point for further understanding and development of more realistic and accurate Mobility Models for VANET simulations.

The Author "Aamir Hassan" [2] in May 2009 uses a simulator tool, which is simple, easy and cheap for vehicular safety. In VANET traffic and network simulator are used together to perform the test. A good simulator is needed to analyze the effect on external communication. So first of all study of current simulators is done and then simulation is performed.

\section{MOBILITY MODELS}

VANET is characterized as a special class of Mobile Ad hoc Networks (MANETs), which consists of number of vehicles with the capability of communicating with each other without a fixed infrastructure. [10]. A Mobility Model needs to be a Realistic Mobility Model that considers the characteristics of the real world scenario either by taking a real world MAP obtained from TIGER (Topologically Integrated Geographic Encoding and Referencing) database from U.S. Census Bureau or by taking Satellite images of Google Earth into consideration to simulate a realistic network.

\section{TYPES OF MOBILITY MODELS:}

Mobility models needs to be realistic.

Basically mobility models are characterized in 5 different types of models: -

\section{a) Random models}

The mobility parameters like speed of vehicle, destination point etc. is considered random. [11] These models are rather inappropriate for modeling VANET application; however these models are most popularly used. A very limited interaction between vehicles is there in this model. Eg: Freeway model[13], Manhattan model.

\section{b) Flow models}

Here movement of vehicle as a single entity, group entity and entity having probability density function are concerned. Here, there is a small interaction between vehicles and environment. [12] These types of models are used to evaluate traffic and safety related applications. Eg: - IDM, CFM, LWR

\section{c) Traffic models}

Here real traffic situation like intersection point, traffic lights and other trafficking policies are modeled. It is different from flow model as it simply take intersection point or traffic light as obstacle where vehicle decelerate or stop. But in real world vehicle do not pick the path randomly or as everyone else like in flow models but according to its habits like fastest path, low traffic paths. Eg: - SSM, TSM, STRAW models.

\section{d) Behavioral model}

Driver of vehicles are humans. They are not machines and cannot follow a specific behavior in all cases. Local parameters influence Human behavior, rather than some specific behavior. This helps in traffic modeling as human behavior is added. Balmer [12] proposed a behavior model in 2007. These models help us in studying whether the human will follow the traffic advice or not. These types of models are used to study human behavior in any emergency situation. Eg: - Ballmer model.

\section{e) Trace- based model}

In Trace based models instead of developing complex models, we directly extract original mobility pattern from movement traces. These movement traces are gathered through measurement campaigns on bus system (Diselnet) and taxi cabs (Cabspot) Etc. These types of models are basically very new ones and require a lot of work to do upon. These models are used to understand the movement pattern of vehicles so that proper realism can be achieved.[15] Eg: - UDEC model, MMTS model.

Vehicular Mobility Models:

\begin{tabular}{|c|c|c|c|}
\hline Models & $\begin{array}{l}\text { Interaction } \\
\text { with } \\
\text { environment }\end{array}$ & Purpose & $\begin{array}{l}\text { Models lie in } \\
\text { them }\end{array}$ \\
\hline $\begin{array}{l}\text { 1. Random } \\
\text { model }\end{array}$ & $\begin{array}{l}\text { No } \\
\text { interaction } \\
\text { with the } \\
\text { environment. } \\
\text { Do not depict } \\
\text { realism }\end{array}$ & $\begin{array}{l}\text { Traffic safety } \\
\text { and user } \\
\text { applications }\end{array}$ & $\begin{array}{l}\text { RWM, } \\
\text { Freeway, } \\
\text { Manhattan }\end{array}$ \\
\hline $\begin{array}{l}\text { 2. Flow } \\
\text { models }\end{array}$ & $\begin{array}{c}\text { Small } \\
\text { interaction } \\
\text { between } \\
\text { vehicle and } \\
\text { environment }\end{array}$ & $\begin{array}{l}\text { Traffic safety } \\
\text { and user } \\
\text { applications }\end{array}$ & $\begin{array}{l}\text { IDM, CFM, } \\
\text { LWR }\end{array}$ \\
\hline $\begin{array}{l}\text { 3. Traffic } \\
\text { models }\end{array}$ & $\begin{array}{c}\text { Real time } \\
\text { interaction } \\
\text { between } \\
\text { vehicle and } \\
\text { environment }\end{array}$ & $\begin{array}{c}\text { Traffic safety } \\
\text { and } \\
\text { applications }\end{array}$ & $\begin{array}{c}\text { SUMO, } \\
\text { VANETSim }\end{array}$ \\
\hline $\begin{array}{l}\text { 4.Behavior } \\
\text { models }\end{array}$ & $\begin{array}{l}\text { Real time } \\
\text { interaction }\end{array}$ & $\begin{array}{l}\text { Traffic safety } \\
\text { and } \\
\text { applications }\end{array}$ & Ballmer model \\
\hline $\begin{array}{l}\text { 5. Trace/ } \\
\text { Survey } \\
\text { based } \\
\text { models }\end{array}$ & $\begin{array}{l}\text { Real time } \\
\text { interaction }\end{array}$ & $\begin{array}{c}\text { Traffic safety } \\
\text { and } \\
\text { applications }\end{array}$ & $\begin{array}{l}\text { UDEC model, } \\
\text { MMTS model }\end{array}$ \\
\hline
\end{tabular}

\section{ANALYSIS}

To evaluate the performance we have taken four mobility models namely.

a) IM Mobility Model: IDM_IM (Intelligent Driver Model with Intersection Management Mobility Model) comes in the category of flow models and describes perfectly carto-car and intersection management. It regulates vehicles speed based on movement of neighboring vehicles. Eg. if car in front brakes, the succeeding car slows down. The vehicles slow down and stop at the intersections and act 
according to the traffic lights if present. Capacity to take into accounts the human behavior.

b) IDM_LC Mobility Model: IDM_LC (Intelligent Driver Model with Lane Changing Mobility Model) comes in the category of flow models. Also vehicles can change lanes and perform overtaking in the presence of multilane roads. It also regulates the movement of vehicles speed based on the movement of neighboring vehicles.

c) USER_GRAPH Mobility Model comes under trace /spatial mobility models. It describes the generic mobility patterns from real vehicular traces.

d) Traffic Light Mobility Model comes under traffic mobility models. Dijkstra algorithm is used to find out the shortest path, the fastest path or the less crowded path. [14]

Then 3 cases are considered for each mobility model:

I. Performance for each model is calculated by placing no RSU.

II. Performance for each model is calculated by placing RSU each separated by a distance of $500 \mathrm{~m}$.

III. Performance for each model is calculated by placing 6 RSU each separated by a distance of $400 \mathrm{~m}$.
Then performance for each mobility model is evaluated in terms of packet delivery ratio and end-to-end delay.

Simulation Parameters Used

\begin{tabular}{|c|c|c|c|c|}
\hline & IDM_IM & IDM_LC & $\begin{array}{c}\text { Traffic } \\
\text { Light }\end{array}$ & $\begin{array}{c}\text { User } \\
\text { Graph }\end{array}$ \\
\hline $\begin{array}{c}\text { Channel } \\
\text { type }\end{array}$ & Wireless & Wireless & Wireless & Wireless \\
\hline $\begin{array}{l}\text { Routing } \\
\text { protocol }\end{array}$ & AODV & AODV & AODV & AODV \\
\hline $\begin{array}{l}\text { No of } \\
\text { nodes }\end{array}$ & $\begin{array}{c}\text { Case 1- } \\
10 \\
\text { Case 2- } \\
20 \\
\text { Case } 3 \text { - } \\
16\end{array}$ & $\begin{array}{c}\text { Case 1- } \\
30 \\
\text { Case 2- } \\
40 \\
\text { Case } 3 \text { - } \\
36\end{array}$ & $\begin{array}{c}\text { Case 1- } \\
30 \\
\text { Case 2- } \\
40 \\
\text { Case } 3 \text { - } \\
36\end{array}$ & $\begin{array}{c}\text { Case 1- } \\
50 \\
\text { Case 2- } \\
60 \\
\text { Case } 3 \text { - } \\
56\end{array}$ \\
\hline $\begin{array}{c}\text { Max } \\
\text { speed of } \\
\text { nodes }\end{array}$ & 3.402 & 3.402 & 3.402 & 3.402 \\
\hline
\end{tabular}

\section{SIMULATION RESULTS}

Values of each mobility model on placement of RSUs at different distances is shown as.

\begin{tabular}{|c|c|c|c|c|c|c|c|c|c|c|c|c|}
\hline & \multicolumn{3}{|c|}{ IDM_IM } & \multicolumn{3}{|l|}{ IDM_LC } & \multicolumn{3}{|c|}{ USER GRAPH } & \multicolumn{3}{|c|}{ TRAFFIC LIGHT } \\
\hline $\begin{array}{l}\text { Cases } \\
\text { with } \\
\text { different } \\
\text { RSU }\end{array}$ & $\begin{array}{l}\text { No rsu } \\
\text { present }\end{array}$ & $\begin{array}{l}\text { Rsu } \\
\text { placed } \\
\text { at } \\
400 \mathrm{~m} \\
\text { apart }\end{array}$ & $\begin{array}{l}\text { Rsu } \\
\text { placed } \\
\text { at } \\
500 \mathrm{~m} \\
\text { apart }\end{array}$ & $\begin{array}{l}\text { No rsu } \\
\text { present }\end{array}$ & $\begin{array}{l}\text { Rsu } \\
\text { placed } \\
\text { at } \\
400 \mathrm{~m} \\
\text { apart }\end{array}$ & $\begin{array}{l}\text { Rsu } \\
\text { placed } \\
\text { at } \\
500 \mathrm{~m} \\
\text { apart }\end{array}$ & $\begin{array}{l}\text { No rsu } \\
\text { present }\end{array}$ & $\begin{array}{l}\text { Rsu } \\
\text { placed } \\
\text { at } \\
400 \mathrm{~m} \\
\text { apart }\end{array}$ & $\begin{array}{l}\text { Rsu } \\
\text { placed } \\
\text { at } \\
500 \mathrm{~m} \\
\text { apart }\end{array}$ & $\begin{array}{l}\text { No rsu } \\
\text { present }\end{array}$ & $\begin{array}{l}\text { Rsu } \\
\text { placed } \\
\text { at } \\
400 \mathrm{~m} \\
\text { apart }\end{array}$ & $\begin{array}{l}\text { Rsu } \\
\text { placed } \\
\text { at } \\
500 \mathrm{~m} \\
\text { apart }\end{array}$ \\
\hline PDR & $\begin{array}{l}67.391 \\
3 \\
\end{array}$ & $\begin{array}{l}83.783 \\
8 \\
\end{array}$ & $\begin{array}{l}65.909 \\
1 \\
\end{array}$ & $\begin{array}{l}95.037 \\
2 \\
\end{array}$ & $\begin{array}{l}69.230 \\
8 \\
\end{array}$ & 50 & 98.95 & $\begin{array}{l}98.832 \\
3\end{array}$ & $\begin{array}{l}97.468 \\
4\end{array}$ & $\begin{array}{l}99.568 \\
4\end{array}$ & $\begin{array}{l}99.744 \\
7\end{array}$ & 99.186 \\
\hline $\begin{array}{l}\text { Avg. } \\
\text { End-to- } \\
\text { end } \\
\text { Delay(m } \\
\text { s) }\end{array}$ & 526.95 & $\begin{array}{l}168.37 \\
2\end{array}$ & $\begin{array}{l}549.38 \\
1\end{array}$ & $\begin{array}{l}171.27 \\
5\end{array}$ & $\begin{array}{l}61.784 \\
1\end{array}$ & $\begin{array}{l}55.252 \\
4\end{array}$ & $\begin{array}{l}300.30 \\
3\end{array}$ & $\begin{array}{l}278.05 \\
7\end{array}$ & $\begin{array}{l}353.52 \\
8\end{array}$ & $\begin{array}{l}78.828 \\
1\end{array}$ & $\begin{array}{l}86.405 \\
9\end{array}$ & $\begin{array}{l}94.542 \\
5\end{array}$ \\
\hline
\end{tabular}

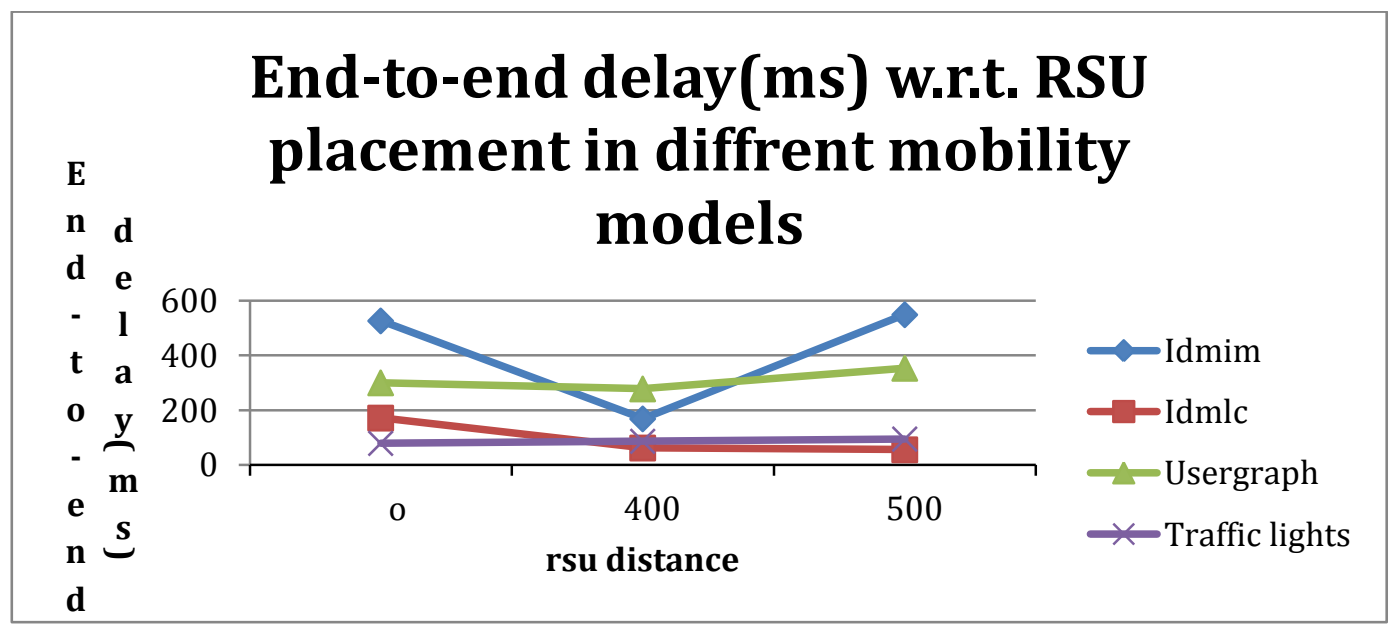




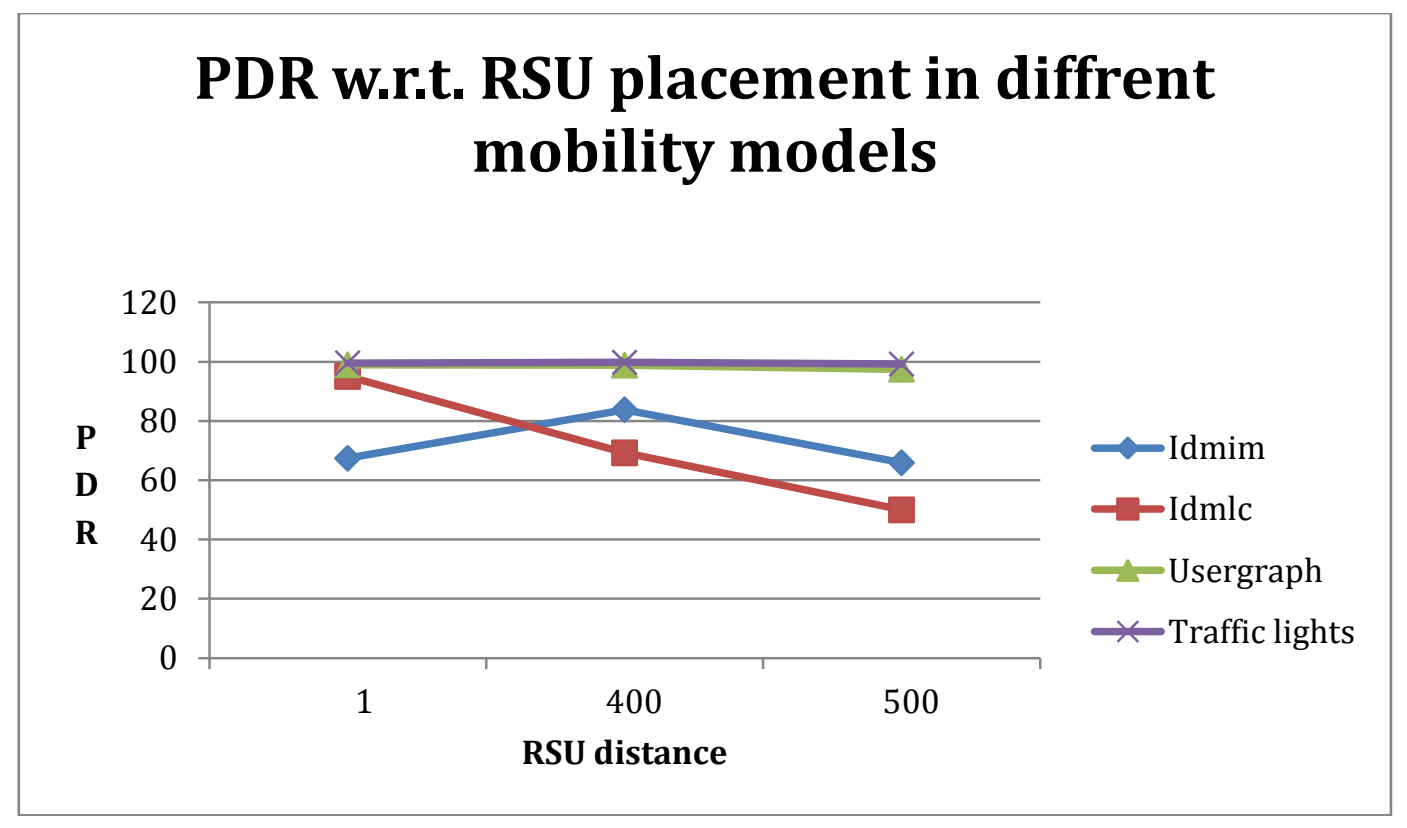

\section{CONCLUSION}

IDM_IM mobility model and User Graph Mobility Model gives better PDR and end-to-end delay when the distance between the RSU is kept at $300 \mathrm{~m}$. There is no need to place RSU in IDM_LC Mobility Model and in Traffic Light mobility model RSU's are kept at a distance of $300 \mathrm{~m}$ or $400 \mathrm{~m}$ for better communication. So by judging the distance of placing RSU's according to the type of mobility models will be a beneficial research.

\section{REFERENCES}

[1] Irina Tal and Gabriel- Miro Muntean, "User-oriented Cluster-based Solution for Multimedia Content Delivery over VANETs", 2011, IEEE.

[2] "Mobile Networks", (IJWMN) Vol. 4, No. 1, February 2012

[3] Uma Nagaraj, Dr. M. U. Kharat, Poonam Dhamal "Study of Various Routing Protocols in VANET" ,IJCST, Vol. 2, Issue 4, Oct . - Dec. 2011

[4] Sandeep Tayal and Malay Ranjan Tripathy "VANETChallenges in Selection of Vehicular Mobility Model" ,2012,IEEE.

[5] Nidhi and D.K.Lobiyal " Performance Evaluation of Realistic VANET using Traffic Light scenario", International Journal of Wireless \& Mobile Networks,(IJWMN) Vol. 4, No. 1, February 2012.

[6] Mobile Networks",(IJWMN) Vol. 4, No. 1, February 2012

[7] Francesco Lupi, Veronica Palma, and Anna Maria Vegni "Performance Evaluation of Broadcast Data Dissemination over VANETs" Department of Applied Electronics, University of Roma Tre, Rome, Italy,2012

[8] Kun-chan Lan and Chien-Ming Chou, "Realistic Mobility Models for Vehicular Ad hoc Network (VANET) Simulations", 2007 IEEE.

[9] Atulya Mahajan, Niranjan Potnis, Kartik Gopalan and An-I A. Wang ,"Urban Mobility Models for VANETs",2005,IEEE.
[10] Sandeep Tayal, Malay Ranjan Tripathy, "VANETChallenges in selection of Vehicular Mobility Model" 2012 Second International Conference on Advanced Computing \& Communication Technologies,2012.

[11] Djamel Djenouri , Wassim Soualhi , Elmalik Nekka "VANET's Mobility Models and Overtaking: An Overview",2007,Springer.

[12] Nayana. P.Vaityi and DN Yaneshwar. V. Thombre “ A survey on vehicular mobility modelling : flow modelling" International Journal of Communication Network Security ISSN: 2231 - 1882, Volume-1, Issue4,2012

[13] Payne H "Freeway Traffic Control and Surveillance Model". Journal of the Transportation Engineering Division 99, 767-783,1973, IEEE.

[14] Balmer M 2007 "Travel demand modeling for multiagent traffic simulations: Algorithms and systems", $\mathrm{PhD}$ thesis, ETH Zurich, Switzerland.

[15] Feliz Kristianto Karnadi, Zhi Hai Mo, Kun-chan Lan "Rapid Generation of Realistic Mobility Models for VANET" 2007,Springer.

[16] Priyanka Goyal, Vinti Parmar, Rahul Rishi, "MANET: Vulnerabilities, Challenges , Attacks, Application" IJCEM International Journal of Computational,Engineering \& Management, Vol. 11, January 2011.

[17] Jeroen Hoebeke, Ingrid Moerman, Bart Dhoedt and Piet Demeester, "An

[18] Overview of Mobile Ad Hoc Networks: Applications and Challenges” IEEE Press Wiley, New York, 2003.

[19] A Mishra and K.M Nadkarni, security in wireless Ad hoc network, in Book. The Hand book of Ad Hoc Wireless Networks (chapter 30), CRC press LLC, 2003.

[20] Jie Wu , Fei Dai, —Broadcasting in Ad Hoc Networks: Based on Self-Pruninglll, Twenty Second Annual Joint Conferences of IEEE Computer and Communication Societies, IEEE INFOCOM 2003. 